\title{
Meshed acellular dermal matrix: technique and application in implant based breast reconstruction
}

\author{
Dino Zammit ${ }^{1}$, Jonathan Kanevsky ${ }^{1,2}$, Fan-Yi Meng' ${ }^{1}$, Tassos Dionisopoulos ${ }^{3}$ \\ ${ }^{1}$ Plastic Surgery, Faculty of Medicine, McGill University, Montreal, Quebec H3G 1A4, Canada. \\ ${ }^{2}$ Montreal General Hospital, McGill University, Montreal, Quebec H3G 1A4, Canada. \\ ${ }^{3}$ Jewish General Hospital, McGill University, Montreal, Quebec H3G 1A4, Canada. \\ Correspondence Author: Dr. Jonathan Kanevsky, Montreal General Hospital, McGill University, Montreal, Quebec H3G 1A4, Canada. \\ E-mail: jonkanevsky@gmail.com
}

\begin{abstract}
Alloderm was the first acellular dermal matrix used and remains a popular choice among plastic surgeons. However, while the overall surgical outcome of breast reconstruction using alloderm has been a success, the economic burden on the health care system makes it a subject of frequent re-evaluations in cost-effectiveness. Prompted by the high price of $\$ 3,700$ USD for a $6 \mathrm{~cm} \times 16 \mathrm{~cm}$ area, our group proposes the meshing of AlloDerm to decrease the total amount needed for breast reconstruction, while achieving comparable surgical outcomes as using unmeshed alloderm.
\end{abstract}

Key words:

Alloderm; acellular dermal matrix; breast reconstruction; meshing; breast cancer

\section{INTRODUCTION}

The use of acellular dermal matrices (ADM) in breast reconstruction has grown in popularity in the last decade, stemming from the increase in implant based reconstruction requiring adequate lower pole coverage..$^{[1]}$ Our idea of meshing ADM originates from a common surgical technique used for skin grafting.

Skin grafts can be classified broadly into two groups: split-thickness grafts that contain a portion of the dermis, and full-thickness grafts that contain the entire dermis. An advantage of split-thickness grafts over fullthickness grafts is that they can survive in less vascular conditions, but are more prone to contracting. ${ }^{[2]}$ Split-

\begin{tabular}{|l|l|}
\hline \multicolumn{2}{|c|}{ Access this article online } \\
\hline Quick Response Code: & Website: \\
& http://www.parjournal.net \\
& \\
& \\
\end{tabular}

thickness grafts can be processed through meshing, therefore increasing promoting improved adherence to the wound. To date, there have been no reports in the literature on using meshed alloderm routinely for breast reconstruction surgery.

Alloderm is an acellular human tissue matrix derived from cadaveric tissue that exhibits regenerative properties. ${ }^{[3]}$ All donor cells and allergenic epitopes are removed, leaving a collagen scaffold, growth factor receptors, and vascular channels that aid in tissue regeneration with minimum scarring and fibrosis. The utility of alloderm is based on its ability to integrate and promote neovascularization

This is an open access article distributed under the terms of the Creative Commons Attribution-NonCommercial-ShareAlike 3.0 License, which allows others to remix, tweak and build upon the work non-commercially, as long as the author is credited and the new creations are licensed under the identical terms.

For reprints contact: service@oaepublish.com

How to cite this article: Zammit D, Kanevsky J, Meng FY, Dionisopoulos T. Meshed acellular dermal matrix: technique and application in implant based breast reconstruction. Plast Aesthet Res 2016;3:254-6.

Received: 17-12-2015; Accepted: 07-06-2016 


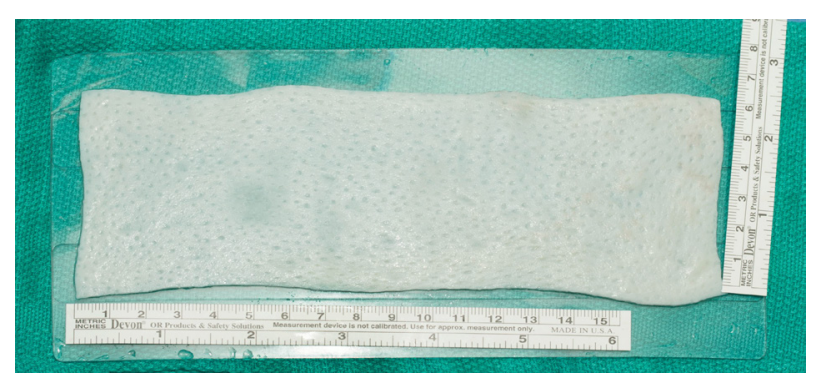

Figure 1: Native alloderm with dimensions of $6 \mathrm{~cm} \times 17 \mathrm{~cm}=102 \mathrm{~cm}^{2}$ and having a thickness of $1.0 \mathrm{~mm} \pm 0.2 \mathrm{~mm}$ (thin type)

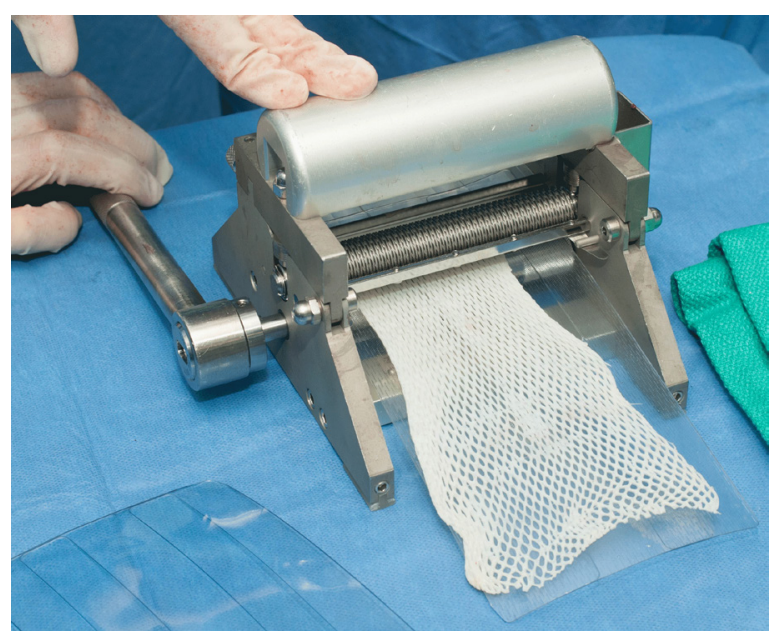

Figure 2: AlloDerm (thin-type) is processed by the skin graft mesher

in the wound bed. ${ }^{[4]}$ It follows the principles of skin graft healing and can therefore be easily incorporated into host tissue as a suitable alternative. These properties make alloderm an excellent support material for breast reconstruction.

Alloderm has been used since 2005. ${ }^{[5]}$ Lower pole coverage was achieved by suturing alloderm to the caudal aspect of the pectoralis major and at the level of the inferior and lateral mammary folds. The benefits of alloderm include reducing implant exposure, visibility and palpability, preventing window shading, better defined inframammary and lateral mammary folds, and allowing for a more natural breast shape. ${ }^{[5]}$

\section{TECHNICAL NOTE}

AlloDerm was initially developed to solve problems with lower pole coverage. Depending on the size of the breast, the quantity of alloderm sheets per operation may vary, leading to increased costs. Meshing alloderm is a novel technique that increases the surface area of usable ADM while maintaining structural integrity.

A sheet of alloderm regenerative tissue matrix (LifeCell Corportation, Branchburg, NJ) measuring $6 \mathrm{~cm} \times 17 \mathrm{~cm}$ $=102 \mathrm{~cm}^{2}$ [Figure 1] and having a thickness of $1.0 \mathrm{~mm}$ $\pm 0.2 \mathrm{~mm}$ (thin type) was prepared in standard fashion by soaking in antibacterial solution and placed on the

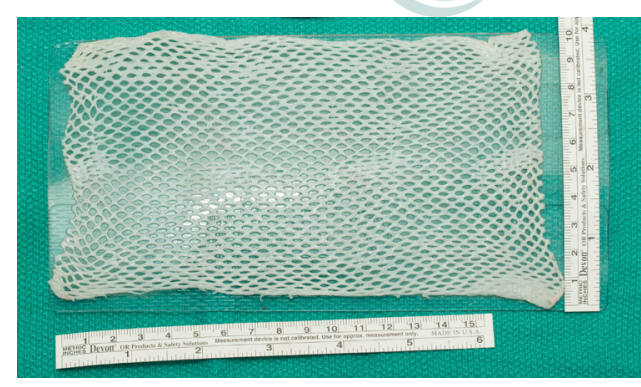

Figure 3: Meshed alloderm with new dimensions of $9 \mathrm{~cm} \times 17 \mathrm{~cm}=$ $153 \mathrm{~cm}^{2}$

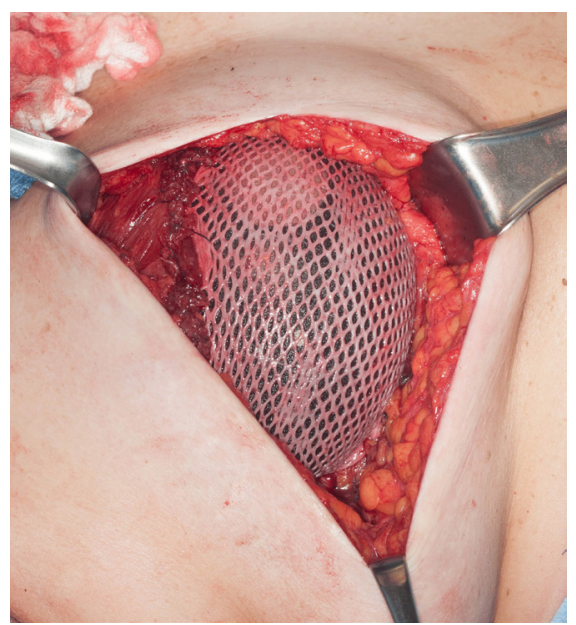

Figure 4: Meshed alloderm is sutured to the pectoralis muscle and the chest wall

skin graft carrier (Zimmer Dermacarrier, Zimmer Surgical Inc., Dover, $\mathrm{OH}$ ). The tissue matrix was passed through the skin graft mesher (Zimmer Surgical Inc.) with a pre-installed roller blade size of 1.5:1 [Figure 2]. Once meshed, it measures $9 \mathrm{~cm} \times 17 \mathrm{~cm}=153 \mathrm{~cm}^{2}$, an increase in surface area of $50 \%$ [Figure 3]. The meshed alloderm is then attached to the chest wall and pectoralis major muscle with PDS 2-0 sutures (Ethicon Inc.), with a tissue expander placed underneath [Figure 4].

\section{DISCUSSION}

The most widely used technique for breast reconstruction employs tissue expanders and implants. ${ }^{[6]}$ When first described, the expander or implant was inserted under the pectoralis major muscle to obtain complete submuscular coverage. If not feasible, the serratus anterior or rectus muscles would be raise to cover the lower pole of the breast. However, using the serratus anterior muscle would often times be associated with donor site morbidity. This includes shoulder pain, weakness and limitation of shoulder elevation due to serratus anterior palsy, in addition to other problems such as wound dehiscence, infection and hematoma formation at donor site closure. ${ }^{[7]}$ Therefore, the dual-plane technique was developed, where the expander or implant was covered by the pectoralis major superiorly and by the dermis of the breast inferiorly. This eliminated donor site morbidity, 
but was associated with the pectoralis major migrating superiorly and causing window shading. In addition, as the inferior pole is covered solely by a thin skin flap, there is a risk of implant migration, poor visibility, palpability, and excessive ptosis. Window shading has since been corrected with marionette sutures to anchor the pectoralis major, while the development of alloderm helped with the problem of lower pole coverage. ${ }^{[2]}$

Meshing of alloderm is an innovative idea that can decrease the costs of its use. A recent study looked at the effects of fenestrating ADMs. ${ }^{[8]}$ Their results showed that with fenestrations, the incidence of capsular contractures, infections and seroma formation were all decreased. Further, they described improved intra-operative fill volumes and expansion rate, as well as a decreased number of postoperative expansions..$^{[8]}$ While not identical in technique to meshing alloderm, it does show potential further benefits for meshing alloderm. By employing a similar technique used with split thickness skin grafts, we were able to take a standard $6 \mathrm{~cm} \times 17 \mathrm{~cm}$ sheet of alloderm and increase its area from $102 \mathrm{~cm}^{2}$ to $153 \mathrm{~cm}^{2}$, an increase of $50 \%$. In our experience, with an increase of $50 \%$ more alloderm available for use, this amounted to savings of approximately $50 \%$ per sheet of alloderm. Intraoperative findings during the second stage (expander to implant exchange) show that the meshed alloderm integrates as well if not better than the standard unmeshed alloderm. This may be because the overall threedimensional surface area of the ADM is increased, allowing for better integration and neovascularization. Further correlation with histological analysis and clinical follow up to compare meshed versus un-meshed ADM is pending.

\section{Financial support and sponsorship}

Nil.

\section{Conflicts of interest}

There are no conflicts of interest.

\section{REFERENCES}

I. Gabriel A, Maxwell GP. Evolving role of alloderm in breast surgery. Plast Surg Nurs 201 I;31:141-50.

2. Shimizu R, Kishi K. Skin graft. Plast Surg Int 2012;2012:563493.

3. Jansen LA, De Caigny P, Guay NA, Lineaweaver WC, Shokrollahi K. The evidence base for the acellular dermal matrix alloderm: a systematic review. Ann Plast Surg 2013;70:587-94.

4. Chauviere MV, Schutter RJ, Steigelman MB, Clark BZ, Grayson JK, Sahar $\mathrm{DE}$. Comparison of alloderm and allomax tissue incorporation in rats. Ann Plast Surg 2014;73:282-5.

5. Glasberg SB, Light D.AlloDerm and strattice in breast reconstruction: a comparison and techniques for optimizing outcomes. Plast Reconstr Surg 2012; 129:1223-33.

6. Wu C, Cipriano J, Osgood G, Tepper D, Siddiqui A. Human acellular dermal matrix (AlloDerm $\circledast$ ) dimensional changes and stretching in tissue expander/implant breast reconstruction. J Plast Reconstr Aesthet Surg 2013;66:1376-81.

7. Dumont CE, Domenghini C, Kessler J. Donor site morbidity after serratus anterior free muscular flap: a prospective clinical study. Ann Plast Surg 2004;52:195-8.

8. Mowlds DS, Salibian AA, Scholz T, Paydar KZ, Wirth GA. Capsular contracture in implant-based breast reconstruction: examining the role of acellular dermal matrix fenestrations. Plast Reconstr Surg 2015;136:629-35. 